\title{
Introduction to Festschrift for Tom R DeMeester
}

\author{
Jeffrey Peters
}

Received: 3 November 2009 / Accepted: 3 November 2009/Published online: 1 December 2009

(C) 2009 The Society for Surgery of the Alimentary Tract

\begin{abstract}
Although there are many measures of a successful surgical career: the patients we treat, the residents we train, the departments we build, or the knowledge we contribute, arguably one of the greatest is the "disciples" we leave behind. Through a career spanning well over 30 years, Tom DeMeester has taken joy and pride in inviting young surgeons from all over the world to join him for a year or two in the pursuit of excellence in the clinical care and research of esophageal and foregut disease. For those of us who had this unique experience (I had the pleasure of being Tom's first clinical esophageal fellow), we found a man with an uncompromising dedication to his work and life, providing an example of excellence not only in clinical care and research but also in life and leisure. Through these fellows, Tom's impact on the field of esophageal disease has been enormous. Through Tom and Carol's generous spirit and example, their impact on our lives has been equally significant.
\end{abstract}

In May 2008, on the eve of Tom's stepping down after 18 years as Chairman at the University of Southern California, we brought together these fellows along with a few friends and colleagues to celebrate Tom's contribution to us and to others. Tom has trained 122 esophageal fellows from 28 countries and six of the seven continents. As can be seen from the photograph accompanying this volume, most of them joined us in Pasadena, for a wonderful, once in a lifetime, $48 \mathrm{~h}$ of fellowship. The program included 47 presentations ranging from bile reflux to NOTES. All were excellent, and as a testament to Tom's impact, most were presented by individuals who have helped define the topic. The 18 papers found in this Festschrift volume were selected from among these talks and, as you will see, provide a fitting remembrance of the event and tribute to Tom DeMeester's career. We only regret that we could not publish them all. Enjoy!

Jeff and Charlene Peters

J. Peters $(\bowtie)$

University of Rochester,

Rochester, NY, USA

e-mail: jeffrey_peters@urmc.rochester.edu 